\title{
PRESTACIONES ALIMENTARIAS EN LA VEJEZ MULTIGENERACIONAL: NUEVAS CONSIDERACIONES DEL DERECHO ARGENTINO
}

\author{
FOOD BENEFITS IN MULTIGENERATIONAL ELDERLY: NEW \\ ARGENTINE LAW CONSIDERATIONS
}

\author{
María Isolina Dabove \\ Rosana G. Di Tullio Budassi ${ }^{* *}$
}

\begin{abstract}
RESUMEN: El Derecho actual vive atravesado por un fenómeno demográfico nunca visto en tiempos precedentes, el envejecimiento multigeneracional. Fenómeno complejo y curioso, cuyos rasgos están determinados por el envejecimiento global creciente y sostenido, tanto como por la presencia de necesidades económicas y culturales particulares, no asumidas suficientemente y que inciden de manera directa en los esquemas tradicionales de responsabilidad jurídica familiar y social frente a la vejez. Este trabajo tiene el propósito de mostrar algunos de estos interrogantes, mediante el análisis específico de la problemática del derecho de alimentos de las personas mayores, en el marco del Derecho de la vejez argentino. A tal fin, observaremos por un lado, cómo afecta y cuáles son los desafíos específicos que el envejecimiento multigeneracional instala en el ámbito del Derecho Privado y, por otro, su impacto en la esfera de la responsabilidad jurídica estatal de la Seguridad Social. Una perspectiva compleja y tridimensional del mundo jurídico, nos ha servido de marco teórico referencial para el desarrollo de esta tarea.
\end{abstract}

Palabras clave: Prestaciones alimentarias, Envejecimiento multigeneracional, Derecho de la vejez en Argentina.

ABSTRACT: The current Law lives crossed by a demographic phenomenon never seen in previous times, the multigenerational aging. Complex and curious phenomenon, whose features are determined by an increased and sustained global aging, as well as, by the presence of particular cultural and economic needs, not enough assumed, that directly affects the traditional patterns of family and social liability in old age. This paper aims to show some of these questions by analyzing the problems about right to food of the elderly, under the Argentine Elder Law. For this purpose, we will observe first how it affects and what are the specific challenges that multigenerational aging install in the field of Private Law and, second, its impact in the field of state legal responsibility of Social Security. A complex and three-dimensional perspective of the legal world, has served as theoretical framework for the development of this work.

Key words: Food benefits, Multigenerational aging, Elder Law in Argentina.

\footnotetext{
* Doctora en Derecho por la Universidad Carlos III de Madrid. Investigadora del CONICET y Profesora de la Facultad de Derecho de la Universidad de Buenos Aires (UBA). Profesora y Directora del Centro de Investigaciones en Derecho de la Ancianidad (Universidad Nacional de Rosario). Profesora en la Universidad Nacional del Centro de la Provincia de Buenos Aires (UNICEN) y en la Universidad Nacional de Córdoba. Av. Figueroa Alcorta 2263. Ciudad Autónoma de Buenos Aires. C.P.: 1425. Argentina. isolinadabove@gmail.com.

** Maestranda en Derecho Privado por la Universidad Nacional de Rosario. Jefe de Trabajos Prácticos de Derecho Civil y de Derecho de la Vejez en la Universidad Nacional de Rosario. Vicedirectora del Centro de Investigaciones en Derecho de la Ancianidad de la Universidad Nacional de Rosario. Profesora de la Universidad Nacional de San Luis. Córdoba 2020, Rosario (Santa Fe) CP: 2000. Argentina. rosanadt@yahoo.com.ar.
} 


\section{ENVEJECIMIENTO MULTIGENERACIONAL Y MODELOS DE RESPONSABILIDAD JURÍDICA FAMILIAR EN LA VEJEZ}

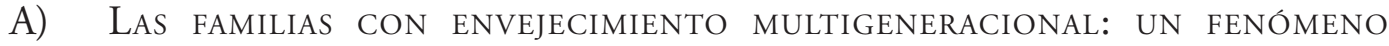 POSTMODERNO}

El Derecho actual vive atravesado por un fenómeno demográfico muy curioso, nunca visto en tiempos precedentes, que bien podría denominarse "envejecimiento multigeneracional", que en este caso observaremos en las relaciones de familia. Este fenómeno, se caracteriza por varios rasgos. Algunos son poblacionales; otros, económicos o bien, son de corte cultural ${ }^{1}$.

Desde el punto de vista poblacional, la realidad nos revela que el aumento demográfico de la población mayor de 60 años es un fenómeno que se ha generalizado en el mundo y que plantea, por tanto, nuevos desafíos a las sociedades de hoy. En Argentina, la expectativa de vida ha crecido notablemente desde las últimas cinco décadas. Así, en 1960 el porcentaje de personas mayores era de un 5, 5\% respecto al total de habitantes. Pero en el año 1991 el porcentaje ascendió a casi un 8,9\% y en el último censo realizado en Argentina en 2010, la población adulta mayor alcanzó el 10,2\%. En tanto, para el 2020 se prevé que los hombres llegarán a alcanzar la edad promedio de 73 años, mientras que las mujeres promediarán los 80 . La proyección para el año 2050 estima que los hombres rondarán los 77 años y las mujeres podrán llegar a los $84^{2}$. Así, “...La notable transición demográfica que se está produciendo hará que para mediados de siglo los porcentajes de la población mundial correspondientes a viejos y jóvenes sean iguales. Según se prevé, el porcentaje de las personas de 60 y más años en todo el mundo se duplicará entre el año 2000 y 2050 y pasará del $10 \%$ al $21 \%$...”3.

Es precisamente la alta y creciente expectativa de vida actual, la que nos ha llevado a detectar un fenómeno cuyo desarrollo solo emerge en este escenario, que hemos denominado envejecimiento multigeneracional. Fenómeno que se configura ante: 1) La coexistencia simultánea de cuatro o tres generaciones de personas, constitutivas de una misma familia: bisabuelos, abuelos, padres e hijos. 2) La convivencia de dos generaciones sucesivas de personas envejecidas y vinculadas por lazos de familia: hijos de sesenta y tantos años, con padres que han superado los ochenta. 3) La coincidencia de dos generaciones alternas de familia: abuelos y nietos ${ }^{4}$.

En el plano económico, el envejecimiento multigeneracional se desenvuelve como un proceso de creciente dependencia. Como señala Bellina Yrigoyen ${ }^{5}$ “....una de las pérdidas que los ancianos deben afrontar se vincula con el cese de sus actividades laborales lucrativas. No solamente las personas hoy están obligadas a jubilarse, sino que un gran porcentaje percibe un beneficio previsional que no llega a cubrir sus requerimientos". En este contexto, poco a

\footnotetext{
1 DABOVE (2008).

2 VV.AA. (Instituto Nacional de Estadísticas y Censos-INDEC, 2012; Organización de las Naciones UnidasONU, 2002; JELIN, 1998).

3 Organización de las Naciones Unidas-ONU (2002).

4 Dabove (2008) pp. 39-54.

5 Bellina Yrigoyen (2004).
} 
poco las generaciones concurrentes tejen entre ellas una compleja red distributiva de recursos, que suele trasladar en la más joven el papel proveedor. Bisabuelos y abuelos con magras jubilaciones y pensiones. Hijos, integrados al mercado de trabajo que subsidian a sus mayores. Nietos jóvenes, que se preparan para ello, cual carrera en posta ${ }^{6}$.

La perspectiva cultural muestra además que el envejecimiento multigeneracional bien puede ser entendido como una variante del multiculturalismo, del pluralismo político y del plurijuridismo ${ }^{7}$. Cada generación esgrime en su haber una forma de entender la vida, códigos de convivencia y prácticas discursivas que le son propios, experiencias políticas diversas, memorias colectivas diferenciables entre sí y valores específicos. Estas culturas interactúan entre sí, se "arrastran" de un grupo a otro, dialogan y compiten, sedimentan y estratifican en un universo heterogéneo de significaciones ${ }^{8}$.

El envejecimiento multigeneracional es, pues, un fenómeno complejo. Nace con los cambios demográficos de la segunda mitad del siglo XX. Se alimenta del aumento de la esperanza de vida, que permite la convivencia simultánea de varias generaciones. Pero también se consolida - como dice Bobbio9-, con el devenir del "tiempo de los derechos" y la creciente conciencia del pluralismo jurídico. Es, en suma, un fenómeno social: multitemporal, plurieconómico y multicultural.

Este trabajo se propone mostrar, precisamente, el alcance de algunos de los interrogantes que el envejecimiento multigeneracional plantea respecto del derecho de alimentos de las personas en su vejez. Para ello se tomará en cuenta la situación argentina, ya que, ella bien puede considerarse un estándar jurídico del Derecho Continental latinoamericano y europeo. Dentro de este escenario, se observará la relación existente entre los diversos tipos de familias y los modelos de responsabilidad que les fueron adjudicados por el Derecho hasta el presente. Se analizarán los factores que dieron origen a la estructura actual de las familias multigeneracionales y los planteos específicos que ellas generan, en el ámbito del Derecho Privado y en el de la Seguridad Social. Más también se estudiarán los mecanismos jurídicos que se hayan puesto en marcha para permitir su adaptación a esta nueva realidad.

Por último, es importante destacar que estos nuevos modelos de familias ponen en cuestión al mundo jurídico en su conjunto. De manera tal que se deja para una próxima oportunidad, el análisis del impacto que el envejecimiento multigeneracional también está ocasionando en materia de capacidad, salud, consumo, acceso y protección jurídica de la vivienda, residencias gerontológicas, recreación, turismo, educación, redes de apoyo y cuidados, políticas gerontológicas; entre las muchas problemáticas que abarcan el Derecho de la Vejez como nueva especialidad jurídica ${ }^{10}$.

\footnotetext{
${ }^{6}$ VV.AA. (Di Tullio Budassi, 2008, pp. 64-82; Herrera, 2011, pp. 4-20; Fama y Herrera, 2008; Calvo Ortega y García Calvente, 2007; Ciuro Caldani, 1992, pp. 35-40; Ciuro Caldani, 1995, pp. 7-11; Bazo, 1993, pp. 181-192; Instituto de Mayores y Servicios Sociales, 1990).

7 VV.AA. (Taylor, 1993; Kymlica, 1995; Briones, 1998; Prieto Sanchís, 1994, pp. 367-387; Geertz, 2006; SARTori, 2001; Yturbe, 2008).

8 De Souza Minayo (2006) pp. 47-59.

9 Bobbio (1991).

10 Dabove y Prunotto Laborde (2013).
} 
La historia del Derecho de la Vejez y del Derecho de Familia nos revela la existencia de tres modelos de responsabilidad jurídica familiar ante la ancianidad, vinculados entre sí, dialécticamente. El modelo totalitario, el modelo abstencionista y el modelo paternalista. El modelo totalitario nace en la antigüedad y se extiende a la Edad Media. El modelo abstencionista se gesta en la modernidad, pero se sucede a lo largo de todo el siglo XIX. En tanto que, el modelo paternalista, se impone con el Estado de Bienestar del siglo XX y llega incólume a la década del 80 de nuestro tiempo. Cada uno de ellos hace referencia a un modelo conceptual de responsabilidad jurídica familiar frente a la vejez.

El modelo totalitario se desarrolló sobre cuatro presupuestos: A) Un concepto de estado fuerte o, incluso, autoritario. B) Una sociedad, con baja esperanza de vida, dividida en clases o estamentos fijos. C) Una estructura familiar rígida, organizada en torno a la figura del "pater". D) Un concepto mediatizado de la vejez, fuertemente ambivalente y estereotipado. En este modelo, el sistema operativo de responsabilidad jurídica familiar se ordena con el fin de garantizar la supervivencia del grupo. Por ello, cada sujeto resulta mediatizado en relación al grupo ${ }^{11}$.

El modelo abstencionista, por su parte, se instalará poco a poco, de la mano de las filosofías pactistas de la modernidad y del Estado liberal. La burguesía se consolidará como nueva clase, las familias actuarán como un factor económico importante, dando lugar a la etapa histórica de la producción y la manufactura en el pequeño taller familiar ${ }^{12}$. Pero, la vejez será objeto de desprecio y marginación por ser sinónimo de inutilidad. Dentro de este modelo, en los siglos XVI y XVII, Inglaterra dará origen a un creativo sistema de ayuda pública para indigentes, conocido como el Derecho de Pobres Isabelino ${ }^{13}, 14$. Así, con este sistema se ponen en marcha por primera vez en el Derecho occidental, dos principios operativos de responsabilidad jurídica respecto al cuidado de las personas mayores. De un lado, se mantendrá el ya tradicional principio de la responsabilidad familiar en materia asistencial, por el cual hijos y nietos quedaban expresamente obligados a prestar alimentos y atención a sus mayores, padres o abuelos, respectivamente. Pero de otro, se habilita la obligación estatal de brindar socorro público, en forma subsidiaria a la imposibilidad de hacerlo las familias ${ }^{15}$. Los Códigos Civiles del siglo XIX recogen este modelo y así llega al sistema jurídico argentino. Así, la familia patriarcal extendida entrará en crisis, para ir dando paso, poco a poco, al modelo de familia nuclear, matrimonial ${ }^{16}$.

\footnotetext{
11 Dabove (2002).

12 Bossert y Zanonni (2013).

13 Este Sistema fue precedido por un complejo entramado normativo: el Statute of 1531 de Enrique VIII; el Statute of Artificers de 1562, el Statute of Aprenntices de 1563; la Ley de 1572; la Ley de 1576; el Act for the Releife of the Poor de 1598, hasta llegar al Poor Law Act de 1601, que logra unificar la legislación anterior, con resultados más eficaces que fueron tomados como modelo por países de la región.

14 VV.AA. (Dabove, 2002; Lebrun, 1992, pp. 71-112; Trevelyan, 1946; Moix Martínez, 1986; Garcés FeRRER, 1992; BRAUDEL, 1986).

15 VV.AA. (Dabove, 2002; Moix Martínez, 1986).

16 Fanzolato (2007).
} 
En el modelo paternalista, la familia amplia dará paso a la familia nuclear -matrimonial-, al tiempo que se instalarán nuevas formas de organización social e institucional y nuevos conceptos de vejez. En este sentido, cabe recordar que la presencia de los ancianos en la ciudad será mucho más rara, como no sea a título temporal, ya que sus hijos se reparten el alojamiento de sus padres en razón de sus distintas posibilidades materiales: las comodidades del hogar, la disponibilidad económica, el tiempo, y un largo etcétera. En este encuadre, a cada personaje familiar le quedará asignado un papel rigurosamente establecido. Y, en muchos casos, será al abuelo a quien se recurrirá como colaborador principal en el cuidado de los más pequeños. A medida que la urbanización progresa, la familia nuclear se afianza en su papel de célula social. Garantía de moralidad natural, unidad de producción económica, es también un nombre, una sangre y un lugar en el mundo para cada individuo ${ }^{17}$. Este será el entramado sobre el cual se impondrá el modelo paternalista de responsabilidad en la vejez, hasta adquirir forma jurídica con el Constitucionalismo Social y el Estado de Bienestar del siglo XX. El nuevo continente no escapará a este proceso, sufriendo la misma suerte que la pergeñada en los Estados europeos ${ }^{18}$. El sistema operativo del modelo paternalista se basó, pues, en principios jurídicos asistencialistas, que intervenían y avanzaban sobre la vida familiar. El cuidado de los mayores ya no quedó librado al campo exclusivo del Derecho Privado, como ocurría en la modernidad. En este tiempo, la responsabilidad familiar será compartida con la acción estatal, quien actuará a la par, mediante el desarrollo de políticas públicas constitucionalmente asumidas. Así, desde fines del siglo XIX, las familias contarán, frente a las contingencias del envejecimiento, con el derecho de la seguridad social, con las primeras pensiones y jubilaciones ${ }^{19}$.

\section{C) LOS MOdelos actuales de las Familias MUlTigeneracionales}

En la postmodernidad, varios fenómenos generaron, a su vez, la crisis del modelo paternalista de responsabilidad jurídica familiar. La tendencia creciente y sostenida hacia el envejecimiento de la población. El aumento de la proporción de personas adultas y ancianas. La disminución de hogares jóvenes y el incremento de familias integradas por personas de edad; los nuevos patrones económicos de producción y la crisis del Estado de Bienestar, son solo algunos ejemplos de ello $^{20}$. Pero también, estos fenómenos indican la presencia de un nuevo escenario familiar: el envejecimiento multigeneracional, en el marco de una sociedad consumista ${ }^{21}$. En esta nueva realidad, dos modelos de responsabilidad jurídica familiar en la vejez, parecen abrirse camino. De un lado, el modelo líquido y residual, propio de las sociedades insertas en el proceso de globalización/marginación. De otro, el modelo comunitarista o incluyente, que nace al cruce del anterior.

El modelo líquido da cuenta de un mundo actual que parece organizarse sobre la base de vínculos sociales y familiares cambiantes, desestructurados, livianos y poco com-

17 VV.AA. (Dabove, 2002; Fanzolato, 2007).

18 JELIN (1998).

19 VV.AA. (Dabove, 2002; Moix Martínez, 1986; Montero García, 1988).

20 VV.AA. (Jelin, 1998; Daniels, 1988).

21 BaUman (2006a) (2007a). 
prometidos entre sí. BAUMAN²2 denominó este fenómeno: “modernidad líquida”. En este marco, escribe: las pautas y configuraciones ya no están "determinadas", y no resultan "autoevidentes" de ningún modo; hay demasiadas, chocan entre sí y sus mandatos se contradicen. En las sociedades líquidas cinco cuestiones vitales aparecen como referentes de la preocupación cotidiana: el problema de la emancipación, la individualidad, la percepción del tiempo/espacio, el trabajo y la comunidad ${ }^{23}$. Pero todos, a su vez, se identifican por el creciente imperio de la autonomía de la voluntad, particularmente en el aspecto patrimonial ${ }^{24}$.

En este marco, pues, el Derecho de Familia ha ido igualando, por ejemplo, la posición jurídica de los esposos entre sí, ha democratizado el ejercicio de la patria potestad, ha nivelado el estatus de los hijos nacidos fuera del matrimonio, ha reconocido el "interés superior del niño" y la necesidad de "fortalecer y empoderar a los mayores"25, como bastión del ejercicio de los derechos fundamentales familiares, entre otras muchas reformas ${ }^{26}$. Asimismo, se fueron desarrollando modelos nuevos de familia, tales como: la familia nuclear ensamblada; la familia matrimonial sin descendencia; la familia nuclear extramatrimonial; las convivencias estables, sin hijos; la familia monoparental; la familia binuclear; la familia protectriz; el matrimonio homosexual; las uniones de hecho y las convivencias de ayuda mutua ${ }^{27}$.

Sin embargo, la realidad de la responsabilidad jurídica familiar en la vejez, muestra asimismo que en esta sociedad líquida, no siempre es cierto que todos los sujetos puedan acceder formal y materialmente a un mayor grado de independencia personal. Junto a los pocos actores que llegan a adquirir la tan ansiada autonomía, se aglutinan verdaderas masas de "desperdicios o despojos humanos" 28 . Personas que jamás alcanzarán su inclusión en el circuito de exigencias que la vida de consumo ha establecida como válida. Entre estos seres, se encuentran en número creciente los viejos, sujetos especialmente débiles, incluso dentro del territorio del mundo jurídico familiar ${ }^{29}$. En este sentido, resulta llamativo observar la escasa cantidad de fallos publicados en Argentina, referidos a reclamos de alimentos de personas de edad, a conflictos con geriátricos, al incumplimiento familiar del derecho de visita a los padres y abuelos. Tampoco hay profusa jurisprudencia que se refiera a las violaciones cotidianas a la integridad física y moral de los ancianos y a la violencia familiar, a la interposición abusiva de acciones de insania o al mal desempeño de la tutela y curatela, entre

\footnotetext{
22 BaUMAN (1999) (2007b).

23 Bauman (1999) (2000) (2006b) (2007a).

24 Di Tullio Budassi (2008) pp. 64-82.

25 VV.AA. (Dabove, 2002; Dabove y Prunotto Laborde, 2013; Iacub, 2011, 2012).

26 VV.AA. (Bossert y Zanonni, 2013; Méndez Costa, 1983, p. 315; Méndez Costa, 2000; Borda, 1989; Méndez Costa y D’Antonio, 2001; Belluscio, 1987; Zanonni, 1993; Dabove, 1999, pp. 1165-1172; CórDOBa y SOlari, 1990, p. 1189; BOSSERT, 2004).

27 Fanzolato (2007).

28 BAUMAN (2006a).

29 VV.AA. (Di Tullio Budassi, 2008, pp. 64-82; Dabove, 2002; Ciuro Caldani, 1992, pp. 35-40; Ciuro Caldani, 1992, 1995; Fanzolato, 1996, pp. 11-40).
} 
otros. Al tiempo que también resulta llamativo, el escaso interés estatal en el desarrollo de normativas nacionales que fortalezcan decisivamente el estatus jurídico de los mayores ${ }^{30}$.

En suma, en el modelo líquido de responsabilidad jurídica familiar en la vejez, se observa un notable doble discurso. Por un lado, se entroniza a la autonomía de la voluntad como enclave del ejercicio de los derechos familiares. Pero de otro, nuestro tiempo va transformando y con ello, arrasando y diluyendo, valores que antaño encontraban solidez y contención en las familias. En el modelo líquido de responsabilidad jurídica familiar, la solidaridad, el respeto, la justicia y el amor se enfrentan al mismo tiempo con el avance de otros valores, especialmente, el de la utilidad, la belleza y la salud encarnadas en la vida joven. Por ello, no resulta infrecuente que en este marco cultural, la debilidad y la soledad que muchas veces padecen los ancianos de este tiempo, hagan que a menudo se los tome como medios y no como fines en sín .

Como contrapartida a este paradigma, otra perspectiva de la responsabilidad jurídica familiar en la vejez se alza en este tiempo: el modelo comunitarista. Este esquema comparte la perspectiva democrática y autonomista de la responsabilidad jurídica familiar en la vejez que propone el modelo líquido estudiado. Pero se aleja de él, en la medida en que también pretende el desarrollo de sociedades y familias "incluyentes". Sociedades y familias, para todas las edades. A tal fin, el modelo comunitarista aboga por la participación activa de los Estados a través del diseño y ejecución de políticas públicas igualitaristas. Caminos de acción comunitaria que desarrollen el sentido de pertenencia de los ancianos al grupo familiar y social, que sostengan actitudes de no discriminación, tanto como de inclusión participativa de los mayores y sus parientes ${ }^{32}$.

Ejemplos concretos de herramientas operativas de este modelo de responsabilidad familiar, los podemos encontrar en el Plan de Acción Internacional de Viena sobre el envejecimiento, promulgado por la Organización de las Naciones Unidas (ONU) ${ }^{33}$. En este documento se señalan los principios lo que inspiran, el alcance internacional y regional, los objetivos de desarrollo y humanitarios vinculados al respeto por los derechos humanos en esta materia. Así como también establece una serie de recomendaciones para la acción para los Estados firmantes. Entre las cuestiones tratadas cabe mencionar los derechos de las personas mayores relativos a: salud y nutrición (rec. 1 a 17); la protección de los consumidores ancianos (rec. 18); vivienda y medio ambiente (rec. 19 a 24); el papel de la familia (rec. 25 a 29); el bienestar social (rec. 30 a 35); la seguridad del ingreso y empleo (rec. 36 a 43) y la educación en la vejez (rec. 44 a 50). Sin embargo, es de hacer notar que este modelo comunitarista, aunque constituye un avance del modelo anterior, se apoya casi hegemónicamente, en el marco de las políticas públicas para su desarrollo, sin visibilizar del todo, la necesidad de transformar estas políticas en derechos humanos completos, es decir, constitucionalmente protegidos. En suma, estas políticas funcionan como directrices o planes de acción estatal. Pero no dan lugar al reconocimiento formal en sentido "fuerte" de los dere-

\footnotetext{
30 VV.AA. (Dabove, 2002; Di Tullio Budassi, 2008, pp. 64-82; Kemelmajer De Carlucci, 2006, pp. 37-68).

31 VV.AA. (Ciuro Caldani, 1992, pp. 35-40; Dabove, 2002; Di Tullio Budassi, 2008, pp. 64-82).

32 Daniels (1988).

33 Organización de las Naciones Unidas (ONU) (1982).
} 
chos de las personas mayores en igualdad de condiciones que a todas las demás personas que componen la comunidad en cuestión ${ }^{34}$.

\section{PRESTACIONES ALIMENTARIAS EN LA VEJEZ DEL ÁMBITO PRIVADO}

A) Las Respuestas nORMATIVAS DESDE los MODELOS TRADiCiOnALES

El derecho deber de alimentos es una institución jurídica central del Derecho de Familia que se caracteriza por:

- Ser asistencial e irrenunciable -artículo 374 C.C.

- Ser inherente a la persona de acreedor y deudor -artículos 374 y 498 C.C.

- Ser inembargable -artículos 374 y 2076 C.C.

- No poder cederse -artículos 374, 1445 y 1453 C.C., ni transmitirse mortis causa -artículo 374 C.C.

- No poder compensarse, ni transarse -artículo 374 C.C.-

- Ser recíproco -artículo 367 C.C.

- Ser variable según las circunstancias de acreedor y deudor -artículos 370 y 372 C.C.

- Ser irrepetible -artículo 376 C.C.

Por otra parte, cabe recordar que para el Código Civil actualmente vigente en Argentina, la prestación alimentaria se deriva de tres fuentes: los derechos deberes nacidos del matrimonio, la responsabilidad parental y el parentesco. De ellas, solo abordaremos el análisis del derecho deber de alimentos nacidos del parentesco -consanguíneo o afín-, es decir:

- Alimentos entre ascendientes y descendientes entre sí, que adquiere el carácter de obligación subsidiaria en el caso de los abuelos respecto de sus nietos y de los nietos respecto de sus abuelos.

- Alimentos entre hermanos y medio hermanos.

- Alimentos entre parientes en primer grado de afinidad.

Al respecto, el artículo 266 del C.C. argentino reconoce explícitamente la obligación genérica de cuidados que pesa sobre los hijos respecto de sus padres; de modo tal que los hijos deben proporcionarles cuidados en su vejez y, en caso de enfermedad o demencia, proveer a sus necesidades. Esta obligación se extiende además, en favor de los demás ascendientes y una forma de atender a esas necesidades la constituye el aporte de alimentos, respecto del familiar necesitado. Desde el Derecho de la Vejez, los supuestos más problemáticos son aquellos que se derivan de los reclamos de alimentos de los nietos respecto de sus abuelos, tanto como los que surgen de las peticiones de las personas mayores en relación a sus hijos y/o nietos. Por ello, las líneas que siguen están destinadas a analizar más de cerca las causales de esta situación.

34 DWORKIN (1989) (1992). 
La doctrina y la jurisprudencia argentinas han sostenido que el derecho deber alimentario nacido del parentesco obedece a razones de solidaridad humana. En palabras de FANZOLATO $^{35}$ “...cada integrante de un grupo familiar es deudor de todos sus miembros por los beneficios que ha recibido del grupo (cuidados, alimentación, educación...), y al mismo tiempo es acreedor por las consecuencias perjudiciales que pueda sufrir a causa de su pertenencia al conjunto... De esta manera, cada persona tiene un deber pecuniario con su familia... La obligación alimentaria es una manera de pagar y de cobrar los servicios intercambiados..." Pero también, agrega el autor, aun cuando nada se haya recibido de la persona concreta, siempre habrá recibido algo del grupo al cual pertenece, y por ello es que resulta obligado. En términos del Fallo de la Cámara Nacional Civil, Sala $C^{36}$, este derecho configura, además, un deber ético y moral de ayudar al necesitado, más aún cuando se trata de un pariente.

Ahora bien, según el artículo 372 del C.C, la prestación alimentaria comprende lo necesario para la subsistencia, habitación, vestuario y para la atención en las enfermedades. Por ello se entiende por alimentos: el conjunto de medios materiales necesarios para la existencia física de las personas, y en ciertos casos, también para su instrucción y educación ${ }^{37}$. Así, se consideran comprendidos en esta institución, los gastos ordinarios (subsistencia, habitación, vestuario), tanto como los extraordinarios (atención médica, farmacológica, los gastos funerarios del alimentado, gastos de mudanza, material de estudio y litisexpensas) ${ }^{38}$. Sin embargo, esta clasificación deberá atender a la persona mayor en su especificidad valiosa, en su distintividad o unicidad ${ }^{39}$; razón por la cual, los gastos médicos y farmacológicos, tendrán en ocasiones, que ser considerados ordinarios.

Por otra parte, la doctrina y la jurisprudencia argentinas han interpretado este artículo de forma amplia, incluyendo las necesidades morales y culturales ${ }^{40}$. De modo tal que, desde la perspectiva del Derecho de la Vejez, no podemos dejar de mencionar que en el caso del reclamo de alimentos por parte de personas mayores, la cobertura de cuidados domiciliarios, acompañantes terapéuticos e incluso, los costos de vivienda en residencias de larga estadía, pueden ocupar un papel fundamental del contenido de esta prestación.

Los parientes por consanguinidad -ascendientes y descendientes- se deben alimentos entre sí, sin límites de grado, al igual que los hermanos y medio hermanos (artículo 367 del C.C.), y los parientes por afinidad en el primer grado (artículo 368 del C.C.). Sin embargo, el alimentista debe reunir una serie de requisitos a fin de que su reclamo prospere, que están previstos en el artículo 370 del C.C. Deberá demostrar judicialmente, entre otros, su situación objetiva de insuficiencia de medios para satisfacer sus necesidades básicas y su imposibilidad de autoproporcionárselos. Es decir tendrá que acreditar la falta de competencia o habilidad física para obtener recursos por medios propios (por ejemplo:

\footnotetext{
35 Fanzolato (1991).

36 Fallo de la Cámara Nacional Civil, Sala C (1979).

37 VV.AA. (Borda,1989; Méndez Costa y D’Antonio, 2001; Córdoba y Solari, 1990, p. 1189).

38 Belluscio (1987).

39 Dabove (2002).

40 VV.AA. (Bossert, 2004; Méndez Costa y D’Antonio, 2001; Fallo de la Cámara Nacional Civil, Sala D, 1986; Fallo de la Cámara Nacional Civil, Sala G, 1983; Fallo de la Cámara Nacional Civil, Sala F, 1983).
} 
minoría de edad, padecimiento de alguna enfermedad o situación social desventajosa, tal como una grave desocupación generalizada; o bien, la fragilidad derivada de la edad avanzada del reclamante); más que la falta de una ocupación remunerativa en particular ${ }^{41}$.

En el Derecho argentino, las acciones de alimentos entabladas por personas menores de edad y de quienes siendo mayores - pero menores de 21 años y no tengan medios de subsistencia propios, según el Código Civil actual-, podrán dirigirlas contra los abuelos, en subsidio. De modo tal que, respecto de esta posibilidad (es decir, sobre la subsidiaridad de la obligación alimentaria de los abuelos), se han dado largos debates doctrinarios y jurisprudenciales, aguzados por la incorporación de la Convención sobre los Derechos del Niño (artículo 75 inc, 22 de la Constitución Nacional Argentina), a partir de 1994. Así, hay quienes sostienen que, ya se trate del nieto, padre, madre, o bien, padre o madre en representación de su hijo menor de edad, que actúen como "reclamantes", deberán acreditar que han agotado las vías procesales para efectivizar el cobro de alimentos al progenitor obligado. Se señala también que, en miras al interés superior del niño/a reconocido en la Convención mencionada, no puede exigirse el cumplimiento riguroso de esos pasos, ya que tornaría ilusorio y desnaturalizaría el derecho del niño/a la prestación en cuestión. Pero incluso se ha sostenido además que, en virtud del artículo 27 de esta Convención, el artículo 367 del C.C. quedaría derogado, pues en ella no se reconoce la obligación subsidiaria, en caso de no haber sido satisfecho este derecho por parte del principal obligado, en este caso, los padres respecto de los niños/as en cuestión.

Asimismo, cabe recordar que, en Argentina, los alimentos derivados de la responsabilidad parental respecto de los menores de edad solo requieren la comprobación del vínculo. De modo tal que lo mismo acontece en el caso del reclamo subsidiario a los abuelos. Situación en donde se exige de un lado, la corroboración del vínculo de parentesco y, de otro, el incumplimiento del padre o madre obligado; no siendo necesario probar las necesidades del nieto/a. En cambio, cuando el solicitante de alimentos es una anciano, se debe acreditar su imposibilidad de procurárselos y, en caso de poseer algún beneficio previsional, deberá probar que le es insuficiente para subsistir. De manera tal que ello supone que no es preciso probar que el reclamante se encuentra en una situación de absoluta imposibilidad para atender a sus necesidades, pudiendo accionar, entonces, por aquella porción faltante pero necesaria, para completar la satisfacción de las mismas ${ }^{42}$. Al Derecho argentino, además, le resulta irrelevante la causa que hubiese reducido al peticionante a esa situación de necesidad y el propio Tribunal lo ha puesto de relieve cuando ha señalado que: más allá que los enojos hayan enturbiado en el pasado las relaciones entre padres e hijos, es contra la naturaleza y la equidad que los descendientes se nieguen a suministrar alimentos a la progenitora que ahora los necesita ${ }^{43}$. Sin embargo, a nuestro parecer estas circunstancias deberían ser tenidas en cuenta, al momento de disponer el modo de cumplimiento de la prestación.

41 VV.AA. (Méndez Costa y D’Antonio, 2001; Bossert, 2004; Yuba, 2011, pp. 77-87; Méndez Costa, 2000; Lloveras y Salomon, 2009; Salomon y Jáuregui, 2007, p. 605; Menezes Da Costa 2012, pp. 120-132; Oliva GOMEZ, 2012, pp. 142-155; B., L. E. v. C., D. y otra, 2007; C., M. L. v. L., L. R. y otros, 2006; Y., J. D. v. T., A. D. y T. , 2009; A.D.P., en representación de sus hijos menores A. F., J. C. y M. E. F. c. A. A. F. y N. R. G., 2010).

42 Bossert (2004).

${ }^{43}$ C. de T., J. E. C/ T., N. y otro (1981). 
El Proyecto de Reforma de Código Civil y Comercial del año 2012, enrolado en la doctrina internacional de derechos humanos, regula los alimentos derivados del parentesco de forma similar a la legislación vigente. Es decir, continúa el modelo de responsabilidad jurídica familiar atendiendo a la estructura demográfica tradicional. Pero, ha adaptado la terminología a los avances que se han logrado en el campo del Derecho de Familia.

Así, al establecer el derecho deber alimentario prevé que se deben alimentos: Art. 537. "Los parientes se deben alimentos en el siguiente orden: a) los ascendientes y descendientes. Entre ellos, están obligados preferentemente los más próximos en grado; b) los hermanos bilaterales y unilaterales. Entre ellos los alimentos son debidos por los que están en mejores condiciones para proporcionarlos. Si dos o más de ellos están en condiciones de hacerlo, están obligados por partes iguales, pero el juez puede fijar cuotas diferentes, según la cuantía de los bienes y cargas familiares de cada obligado". Como vemos, este artículo es semejante al artículo 367 C.C., aunque añade la salvedad que ante el caso de parientes que se encuentren en condiciones de aportar alimentos, el juez tendrá libertad de fijar cuotas diferentes teniendo en cuenta las cargas familiares y los bienes de cada obligado. Cuestión esta que ya venía siendo receptada en la jurisprudencia.

Respecto del contenido de la obligación alimentaria, el artículo 541 del Proyecto es semejante al artículo 372 del C.C., con la única diferencia de que añade una frase final, donde explicita que si el alimentado es una persona menor de edad, comprende, además, lo necesario para la educación. Situación de la que también se ha ocupado la jurisprudencia. Así, el artículo 541 del Proyecto señala: "Contenido de la obligación alimentaria. La prestación de alimentos comprende lo necesario para la subsistencia, habitación, vestuario y asistencia médica, correspondientes a la condición del que la recibe, en la medida de sus necesidades y de las posibilidades económicas del alimentante. Si el alimentado es una persona menor de edad, comprende, además, lo necesario para la educación”.

Ahora bien, aunque el Proyecto no parece receptar los nuevos modelos de familias multigeneracionales, es preciso resaltar que allí se ha plasmado al menos una norma que ampara la subsidiaridad de la obligación de los abuelos respecto de los nietos. El artículo 668 incorpora una norma procesal que exige la demostración verosímil de las dificultades del actor para percibir los alimentos del progenitor-obligado principal-. En este sentido establece: Reclamo a ascendientes. Los alimentos a ascendientes pueden ser reclamados en el mismo proceso en que se demanda a los progenitores o en proceso diverso; además de lo previsto en el título del parentesco, debe acreditarse verosímilmente las dificultades del actor para percibir los alimentos del progenitor obligado

b) LA APERTURA HACiA EL MODElo LÍQUido EN LA JURisprudencia: LA RESPONSABILIDAD POR ALIMENTOS PARA LA CONSERVACIÓN DE LA AUTONOMÍA PERSONAL EN LA VEJEZ

En Argentina, la recepción del modelo líquido de responsabilidad jurídica parental por alimentos en la vejez con base en el fundamento del resguardo de su autonomía personal (y no solo en virtud del principio de la solidaridad familiar) ha sido fruto de la jurisprudencia reciente. Mas, entre ellos, cabe destacar el caso de M. de H., L. c/H. de F., C. 
$\mathrm{D}^{44}$, en el que la acción fue entablada por una anciana en contra de su hija y su yerno. El a quo resuelve establecer una cuota a cargo de los demandados. Contra esta sentencia apelan ambas partes.

Los demandados esgrimen que la actora no ha demostrado fehacientemente encontrarse en estado de indigencia. Muy por el contrario, se ha acreditado que goza de una jubilación y pensión, cuenta con los servicios de la obra social PAMI, es propietaria de una cuenta bancaria y del inmueble donde habita. En base a estos argumentos solicitan al Tribunal que revoque la sentencia.

Para estimar esta petición, la Cámara realiza un exhaustivo análisis de la situación económica de la alimentada y su estado de salud, a fin de ponderar si la misma puede afrontar su manutención. Así, una vez corroborada la situación patrimonial de la anciana, la Cámara consideró que el caudal económico de esta solo alcanza para hacer frente a las erogaciones que demanda la vivienda, alimentación, vestuario y atención médica. Pero dadas las condiciones de salud y avanzada edad, la reclamante precisa de la asistencia de una empleada al menos medio día, gasto que no le es posible encarar por sus propios medios. Así, motivado en lo precedente, el Tribunal rechaza los agravios de los demandados. Mas, en cuanto a las quejas de la anciana respecto del monto de la cuota que fijara el a quo, la Cámara resuelve que la misma deberá actualizarse mes a mes por el índice de precios del consumidor de la ciudad de Córdoba, a fin de que sea suficiente para abonar los servicios de una asistente de medio día.

A nuestro parecer, el fallo de referencia significó un gran avance en relación al sustento de la autonomía personal de la mujer anciana, y, por esta razón entendemos que este fallo es una muestra representativa del modelo líquido de responsabilidad alimentaria en la vejez. En este sentido, recordemos que los alimentos entre parientes no exigen demostrar el estado de indigencia del peticionante para que prospere la acción. En efecto, solo basta con probar la existencia de cualquier necesidad básica que no pueda ser satisfecha por el reclamante. Sin embargo, en el caso, la primacía de la autonomía personal de la mujer mayor fue justamente valorada entre los parientes en cuestión, incluyendo al pariente afín como obligado a la prestación en igualdad de condiciones que a su hija, consanguínea.

En el caso analizado, la anciana de 77 años funda su demanda en la insuficiencia de sus recursos para contratar los servicios de una persona que la asista. Reclama únicamente, aquello que considera imprescindible para hacer sostener su continuidad en el hogar, y lo plantea en el momento exacto en que su autonomía (o independencia) comienza a declinar. La ayuda económica obtenida por medio de la sentencia, significó para ella ni más, ni menos, que la posibilidad de seguir viviendo en su hogar, lo cual no hubiese podido concretarse sin este sustento. De modo tal que la Cámara priorizó la autonomía personal, la independencia y la salud, cuando el amor y la solidaridad espontánea habían ya declinado para el caso $^{45}$.

Ahora bien, una muestra significativa en relación al modelo comunitarista de responsabilidad alimentaria en la vejez lo constituye, a nuestro juicio, el reciente fallo: G. F.

\footnotetext{
${ }^{44}$ M. de H., L. c/H. de F., C. D (1990).

45 Di Tullio Budassi (2008) pp. 64-82.
} 
C. c/ I. T. M. E. C. s/ alimentos ${ }^{46}$. En este caso, lo interesante se deriva de dos características que muestra con claridad la sentencia referida. De un lado, el escenario jurídico novedoso que plantea el actual fenómeno de las familias multigeneracionales provocado por el envejecimiento global de la población, dado que aquí se trata de un reclamo de alimentos que realiza un hijo de 70 años, respecto de su madre de 91 años. Pero de otro, el fallo expresa también las dificultades del Estado para dar respuesta a la problemática alimentaria, en tanto derecho humano constitucionalmente protegido, priorizándose con ello, el esquema tradicional de responsabilidad iusprivatista familiar. En definitiva, el hijo se ve impelido a actuar contra su madre, frente a un Estado impotente para dar cumplimiento a su deber fundamental de garantizarle "alimentos" a través del régimen de la seguridad social. El modus operandis comunitarista aparece, en el preciso instante en que la Cámara condena a la madre de 91 años a prestarle alimentos a su hijo de 70 años, teniendo en cuenta el lazo comunitario de solidaridad familiar, a pesar de tratarse de dos personas altamente envejecidas. Pero, veamos más fielmente el fallo, transcribiendo lo más fielmente posible su contenido.

El Sr. G. F. C., de setenta años de edad, había reclamado en primera instancia, la fijación de una prestación alimentaria a cargo de su madre insana, de noventa y un años, quien es representada por el curador, designado en el juicio de insania de la madre.

El actor había invocado como fundamento de su pretensión, el hecho de haber recibido de su madre de manera regular aportes económicos que conformaban su principal y único sustento, durante el extenso período en que ella gozó de plena capacidad. Este hecho fue, incluso, admitido por los hermanos del peticionante; sin embargo, el curador de la insana, en ejercicio de su personería en la causa, lo desconoció.

Durante la tramitación del proceso de primera instancia se fijaron alimentos provisorios mensuales, medida que no fue recurrida; y finalmente, la sentencia aumentó la cuota mensual anteriormente estipulada, contra la que se alzaron el actor, la obligada y el Ministerio de Incapaces. En el expediente en cuestión quedó reconocido que la Sra. I.T., madre del peticionante, percibía los frutos de la explotación de un campo que, en los términos en que se decidió en primera instancia, provee rentas excedentes como para cubrir -además de todas las necesidades de la causante- la cuota establecida por la juez de grado. Sobre el punto, se puso de relieve que el actor había consentido, como condición del pago de los alimentos, la cobertura previa de los gastos de manutención de la insana.

La demanda es recurrida por el actor al considerar que la sentencia no trató su pedido de una suma extraordinaria, a abonar por única vez, tendiente a paliar el endeudamiento atrasado al que manifiesta haberse visto sometido. Considera el impugnante que resulta contradictorio que se admita la prestación alimentaria y, concomitantemente, se desestime la prestación por única vez; y ello por entender que la condena al pago de alimentos importa el reconocimiento de la necesidad; de lo que -a su modo de ver- derivaría derechamente la procedencia de tal aspecto de su reclamo.

El apelante también se queja del monto de la cuota establecido. En tal sentido, aduce que el haber percibido de la madre $\$ 228.000$, en el año 2008, pone en evidencia que existía una prestación significativamente mayor antes de la interdicción que la ahora fijada;

46 G. F. C. c/ I. T. M. E. C. s/ alimentos (2012). 
lo que lo lleva a sostener la insuficiencia de la pensión establecida. Por último, cuestiona la imposición de costas en el orden causado. Así, pues, la Cámara considera que "a la luz de lo expuesto, claro está que las sumas que periódicamente la demandada habría abonado al actor durante el tiempo previo a su interdicción no pueden dar lugar a una suerte de derecho adquirido; tal como parece entenderlo el quejoso en su memorial. No existe una obligación legal de mantener al pariente en una situación económica idéntica a la que gozó durante la situación de capacidad de la madre. En la medida en que aquellos pagos existieron sin que hubiese habido una sentencia o un convenio que los reconociera como obligación civil, solo cabe considerar que tales aportes representaron liberalidades de la madre que, en el mejor de los casos, podrían asimilarse al cumplimiento de una obligación natural. De ahí que quien los recibió no puede exigir que tales aportes continúen en idéntico alcance (art. 517 del Código Civil). Lo dicho es sin perjuicio de que ese historial tenga un rol indiciario del nivel de vida del grupo familiar; estándar que a nuestro juicio fue adecuadamente justipreciado por la magistrada de grado al fijar el monto contra el cual se alza el actor".

Por otra parte, en cuanto a las entregas esporádicas que la madre, hoy insana, hacía al pretensor de cierta porción de las utilidades de la explotación rural que ella gestionaba -además del aporte mensual-, la Cámara entiende "que tampoco constituye razón suficiente como para sostener la procedencia del pedido de cuota extraordinaria; esto es, el pago por única vez de veintisiete mil dólares (U\$S 27.000) pretendida por el apelante. De todas maneras" -se agrega en el fallo-, "el invocado y eventual compromiso - no probado- asumido por el reclamante ante presuntos terceros que habrían prestado dinero al actor para atender a sus necesidades, se podría tener por suficientemente cubierto con el cobro que oportunamente percibirá el alimentista como retroactivo de la pensión; y ello de decidirse -como se hará- el mantenimiento de la cuota. Así, pues, queda enervada la eficacia crítica del reproche”.

Ahora bien, como ya hemos señalado con anterioridad, en el contexto normativo en el que se enmarca la cuestión que nos convoca, es la situación de necesidad del reclamante la que motiva el alcance de la prestación. En la medida en que el actor omitió probar la concreta existencia de una deuda que alcance tamaña envergadura, su pretensión no puede ser admitida.

Desde otra perspectiva, continúa el fallo, "no puede soslayar el tribunal que el actor se ha abstenido de producir prueba que permita ponderar su nivel de gastos. No obstante, con saludable criterio, la juez de grado ha estimado un monto que -a no dudarlo- lo ha obtenido de la ponderación de circunstancias de público y notorio conocimiento que permiten apreciar los gastos estimativos para la subsistencia decorosa de una persona de setenta años de edad; desde luego, teniendo en cuenta el estrato socioeconómico como el que caracteriza al del actor y su grupo familiar. En definitiva, las quejas del apelante por la insuficiencia de la cuota establecida a la luz de lo que estaba presumiblemente habituado a percibir con anterioridad, carecen de toda eficacia crítica en tanto importan desconocer el estatuto normativo que caracteriza la prestación alimentaria entre pariente".

Interesantes resultan también los agravios de la demandada y el Ministerio Público. $\mathrm{Al}$ respecto, consideran las recurrentes -expresa el fallo-, que la existencia de un hijo del Sr. G., mayor de edad, sano y joven, que reside en Estocolmo, Suecia, y que percibiría ingresos en una moneda fuerte, enerva la obligación de la madre insana frente al actor. Afirman que 
si bien el pretensor posee el mismo grado de parentesco con la demandada que con su hijo, las mejores condiciones dada su juventud- en las que se encuentra el descendiente deberían haber sido tenidas en cuenta por la juez de grado para desestimar el pedido de alimentos dirigido contra la madre insana.

Pero sobre este aspecto la Cámara señala que: corresponde considerar que cuando dos parientes se encuentran en el mismo grado en relación al alimentista, ambos se encuentran obligados a la prestación. De allí que compete al pretensor la opción de plantear su reclamo indistintamente contra uno, algunos o todos los obligados en idéntico grado. En esa coyuntura, es la parte demandada la que -sea dentro del contexto formal que admite el art. 643 del Código Procesal, sea por vía de incidente de coparticipación de cuota- carga con la demostración de la existencia de otros parientes que, en igualdad de grados, se hallarían en mejores condiciones para proporcionar los alimentos.

Ahora bien en el caso, la parte demandada se limitó a invocar la existencia de un hijo del actor que viviría en el exterior, presumiendo entonces que ello llevaría implicado -debido a la juventud del hijo y a la residencia en un país con "moneda fuerte"- una mejor condición para proveer a la prestación. Sin embargo, no debe ser así cuando -como sucede en la especie- el pretensor ha negado las mejores condiciones de su hijo como para proveer la prestación. Tal como se plantearon las cosas, pues, se advierte la falencia probatoria de la emplazada, quien no ha demostrado el extremo fáctico necesario para eximirse -total o parcialmente- de su obligación; vale decir, que no probó las mejores posibilidades del apuntado hijo para solventar las necesidades del actor; situación que conduce a la desestimación del agravio. A ello debe sumarse el hecho de que sí ha quedado reconocida en la causa la solvencia económica de la demandada; lo cual le permite, tal como fue definida la cuestión, afrontar la prestación establecida sin compromiso de la amplia cobertura de sus propias necesidades; según expresamente lo dispone la resolución en crisis. A este escenario debe sumársele la probada incapacidad laboral acreditada por el actor; a lo que se suma la inexistencia de rentas genuinas que en el caso cabe presumir; sobre todo por no haberse colectado prueba en contrario.

Por último, el curador de la insana y el Ministerio Público objetan la suma establecida como cuota en beneficio del actor ya que: "consideran que debe restringirse a lo que resulta indispensable para atender a sus necesidades”. No obstante, la Cámara consideró que este aspecto del agravio había quedado desierto por cuanto se agota en la mera apreciación subjetiva. Las recurrentes -señala el fallo- entienden, sin exponer argumento o razonamiento lógico alguno, que la suma es excesiva sobre la única base de lo que es su impresión personal. Contrariamente a esa posición, todo indica que el decisum apelado ha ponderado adecuadamente las variables que presenta el caso, el contexto histórico de lo que ha sido el desenvolvimiento de la familia de las partes, el estándar de vida en el que se encuentra posicionado el grupo familiar y los demás antecedentes de autos. La conclusión inevitable es, pues, que la apreciación subjetiva de las apelantes carece de solidez, lo que echa por tierra la eficacia crítica del agravio (conf. doctrina de los arts. 265 y 266 del Código Procesal).

Así, pues, por las razones expuestas el Tribunal resolvió confirmar la sentencia de primera instancia; modificándola exclusivamente en lo relativo a las costas, que se impusieron a la parte vencida. Este fallo considerado in extenso es, sin dudas, significativo para el 
derecho de alimentos por varias razones. De un lado, porque se abre a la construcción de nuevas respuestas jurídicas, con viejas herramientas (es decir, sin salir de las fuentes formales vigentes para el caso), las cuales, como ya dijimos a nuestro juicio, son cercanas al modelo comunitarista de responsabilidad jurídica familiar. Pero además, y al mismo tiempo, plantea nuevos interrogantes respecto del grado de eficacia, legalidad y legitimidad de estos instrumentos tradicionales para hacer frente de manera generalizada y sostenida a este escenario particular de las familias multigeneracionales postmodernas.

En el caso estudiado, la madre de 91 años contaba con una posición económica acomodada que le permitió hacerse cargo de la obligación alimentaria debida a su hijo, de edad avanzada como ella (70 años) e imposibilitado de obtener otro sostén por sí. No obstante, el caso deja abierto el interrogante respecto de las otras familias multigeneracionales, en las cuales haya dos generaciones de personas mayores "jubiladas o pensionadas" -en el mejor de los casos-, carentes ambas del sustento necesario para cubrir los requerimientos alimentarios básicos para la vida. Si las familias multigeneracionales ponen en crisis la solidaridad familiar derivada de la obligación alimentaria entre parientes, urge preguntarse entonces, ¿a quién le corresponderá responder? ¿Al Estado? ¿Al Mercado? ¿Al Voluntariado? ¿A la Sociedad en su conjunto, a través de los tributos? Así, esta serie de interrogantes nos lleva a pensar en la necesidad de articular un modelo superador de esta lógica bipolar (¿la Familia o el Estado?) en la cual estamos habituados a responder cuestión tan delicada como la de las prestaciones alimentarias.

Según hemos visto, la responsabilidad jurídica estatal en materia de alimentos y en materia habitacional ha sido abordada tradicionalmente a través del otorgamiento de subsidios, planes y viviendas sociales. En el cumplimiento de este deber, el Estado decide la adjudicación de estos beneficios en función de una serie de parámetros -ingresos fijos, lazos familiares, redes sociales, edad del peticionante, entre otros-. Si las redes familiares o sociales no son suficientes para garantizar el disfrute de los derechos fundamentales el Estado debe arbitrar los mecanismos necesarios para garantizar el acceso a los alimentos o a la vivienda, en especial a los que por su edad, discapacidad, o desempleo no puedan autogestionarlo. Máxime cuando es sabido que del acceso a estos derechos básicos depende la efectivización de otros derechos fundamentales.

En consonancia con lo expuesto, en el año 2002 se dictó el antecedente del Defensor del Superior Tribunal de Justicia c. Provincia de Entre Ríos ${ }^{47}$, muy debatido en la doctrina por las aristas particulares del caso. El fallo aludido fue dictado por el Juzgado de Menores No 2 de Paraná. La situación fue planteada por el Defensor del Superior Tribunal de Justicia de Entre Ríos, en protección de una mujer y sus hijos menores de edad, quienes se encontraban en una acuciante situación de vulnerabilidad social. La familia, carente de recursos económicos, y luego de acudir a diferentes instancias estatales, no había logrado obtener la asistencia necesaria a sus múltiples necesidades, siendo la más urgente la alimenticia. El Juzgado interviniente obligó al Estado provincial a suministrar los alimentos necesarios para los menores de edad y su grupo familiar. A su vez, se mantuvo vigente una medida cautelar por la cual se le ordenaba a un supermercado proveer productos alimenta-

47 Defensor del Superior Tribunal de Justicia c. Provincia de Entre Ríos (2002). 
rios y de primera necesidad a los reclamantes hasta que el Estado los incluya en un plan de ayuda social ${ }^{48}$.

En otro precedente actual, la Corte Suprema de la Provincia de Buenos Aires dictó un fallo, B.A.F. c/ Provincia de Buenos Aires ${ }^{49}$, que estableció la obligación del Estado provincial y de la Municipalidad de La Plata a responder ante la situación de indigencia de una familia -carencia habitacional y alimentaria-. En sus fundamentos señaló que la sentencia recurrida, que denegó la petición de la familia carenciada, vulnera numerosas normas constitucionales y de instrumentos internacionales de igual jerarquía, particularmente aquellas relacionadas con la protección de derechos económicos, sociales y culturales tales como el derecho a una vida digna, a la alimentación, a la vivienda digna, a la protección de la familia y, en especial, con los derechos del niño.

La justicia ha ponderado las necesidades extremas de las familias reclamantes, $y$ ha determinado que es el Estado quien debe responder por ellas, haciendo efectivo sus derechos consagrados constitucionalmente, independientemente de la existencia de familiares obligados a su sustento. Pues el Estado no puede sustraerse a sus obligaciones de rango constitucional alegando la obligación principal de familiares cuando dicha obligación -establecida en la ley civil y en la ley penal-, emana de una ley inferior a la Constitución Nacional.

\section{PRESTACIONES ALIMENTARIAS EN LA VEJEZ DEL ÁMBITO PÚBLICO}

\section{A) LA INSUFICIENCIA DE LOS MODELOS LÍQUIDOS Y COMUNITARISTAS}

La responsabilidad jurídica familiar de los modelos líquidos y comunitaristas de este tiempo constituyen, sin duda, interesantes intentos de respuesta a la temática del envejecimiento multigeneracional. Sin embargo, no resultan suficientes para este nuevo escenario social y familiar que se organiza además, sobre un nuevo paradigma de Estado: el Estado neoconstitucional. El modelo líquido, carece de la fuerza vinculante derivada del principio de solidaridad social y familiar, en tanto que, el modelo comunitarista parece repetir la fundamentación asistencialista de la Seguridad Social, en cuyo marco, la persona de edad sigue ocupando el lugar de medio y no de sujeto de derecho pleno. En efecto, si bien nuestro sistema reconoce expresamente el carácter "alimentario" de las jubilaciones y pensiones en el art. 14 inc. de la Ley $24.241^{50}$, y así lo ha señalado además, alguna jurisprudencia ${ }^{51}$; lo cierto es que al acceder a esta prestación, la persona mayor sufre de hecho y sin escapatoria jurídica posible, una drástica merma en sus ingresos. Sea ello como fuere, todos los modelos de responsabilidad jurídica familiar sustentados hasta el presente, previos al envejecimiento multigeneracionales, se han desarrollado en base a estas posiciones.

En los modelos totalitarios, la responsabilidad jurídica alimentaria de las personas de edad ha sido planteada, en cabeza casi exclusiva del Estado (para negar, así, a la familia, precisamente en su función de célula social). En los modelos abstencionistas y en los mode-

\footnotetext{
48 VV.AA (Bidart Campos, 2002, p. 267; Ciuro Caldani, 2002, p. 270; Jáuregui, 2002, p. 847).

49 B.A.F. c/ Provincia de Buenos Aires (2013).

50 Ley 24,241, de 1993.

51 W. J. A. c/ F., M. A. s/ (2012).
} 
los líquidos, el sistema de responsabilidad jurídica ha pesado exclusivamente en el ámbito familiar, con la diferencia que, en el modelo abstencionista, el fundamento es la solidaridad familiar. En cambio en el modelo líquido, el sostenimiento de la autonomía personal de la persona mayor. En el modelo paternalista, por su parte: el Derecho ha sustentado un régimen combinado de responsabilidad familiar, en cuanto principal obligado, y ha reconocido al Estado en un papel subsidiario. En el modelo comunitarista, por último, se ha mantenido este esquema de juego pero, se la añadió la responsabilidad político social, a través de un mayor protagonismo del poder administrador, en la materia, mediante el otorgamiento de subsidios, planes o ayudas sociales, entre otras.

Ahora bien, en este tiempo postmoderno, se ha instaurado un nuevo paradigma de Estado y de Derecho que ha sido denominado: "Estado Constitucional de Derecho". Este Estado de hoy, como sabemos, presenta rasgos particulares que condicionan la producción y el funcionamiento del Derecho en su conjunto. De manera tal que cabe reconocer su incidencia en las prestaciones de alimentos ya se trate en su faz pública o privada. Guastini ${ }^{52}$ caracteriza este fenómeno con siete propiedades. 1) La existencia de una Constitución rígida, que incorpora los derechos fundamentales; 2) la garantía jurisdiccional de la Constitución; 3) la fuerza vinculante de la Constitución; 4) su "sobre interpretación" (se interpreta extensivamente y de ella se deducen principios implícitos); 5) la interpretación adecuadora de las leyes; 6) la aplicación directa de las normas constitucionales, también para regular las relaciones entre particulares; 7) la influencia de la Constitución sobre las relaciones políticas, que incluye el control constitucional sobre la discrecionalidad política del legislador. Por ello, entendemos que todas estas características deberían estar presentes en el modelo de responsabilidad jurídica alimentaria en la vejez, tornándolo en modelo iusfundamental ${ }^{53}$.

A nuestro juicio, este modelo iusfundamental de responsabilidad jurídica respecto de las personas de edad tendría que abordar la problemática de los alimentos a la luz de una perspectiva integrativista y sistémica del Derecho, tanto como de la propia vejez. De modo tal que debería abogar por la consolidación de una nueva rama jurídica, que atienda de manera integral los conflictos derivados del envejecimiento poblacional, con base constitucional ${ }^{54}$. Dentro de esta nueva mirada de la problemática jurídica de la vejez, a nuestro modo de ver, el modelo iusfundamental de responsabilidad jurídica debería constituirse bajo la atenta articulación de la participación de todos los actores en juego en materia alimentaria, vale decir: las propias personas mayores, las familias, la sociedad, las instituciones intermedias u ONGs y el propio Estado en su conjunto. Un buen intento de instaurar este nuevo régimen en materia de responsabilidad jurídica en relación a las personas de edad, lo encontramos en el Derecho español, a través de la Ley 3955, referida a la Promoción de la Autonomía Personal y Atención de las Personas en Situación de Dependencia. Caso que

\footnotetext{
52 GuASTINI (2001).

53 VV.AA. (Alexy, 1997, 2008; Prieto Sanchís, 2002).

54 Dabove (2008) pp. 39-54.

55 Ley 39, de 2006.
} 
hemos estudiado en otra oportunidad ${ }^{56}$. No obstante, en el plano internacional también encontramos algunas herramientas formales que pretenden dar cuenta de la necesidad de instaurar este nuevo modelo iusfundamental de responsabilidad respecto de la vejez.

En este sentido creemos que el Segundo Plan de Acción Internacional sobre el Envejecimiento de la Organización de las Naciones Unidas (ONU) (2002) ha comenzado a atender a estos desafíos. Allí, en efecto, se retoman algunas cuestiones señaladas por el Plan de Viena; pero también, introduce nuevas perspectivas acordes con el modelo iusfundamental. Vuelve a resaltar, por ejemplo, la necesidad de desarrollar políticas sociales y jurídicas que asuman de manera plena las cuestiones derivadas de los cambios demográficos. Destaca, también, la importancia de la implementación de "políticas sobre el envejecimiento que incluyan el hecho de la mayor duración de la vida y con un punto de vista que abarque toda la sociedad". Pero se atreve a dar un paso más. Entre sus objetivos y recomendaciones, caben destacar: a) La plena realización de todos los derechos humanos y libertades fundamentales de todas las personas de edad. b) El envejecimiento en condiciones de seguridad, lo que entraña reafirmar el objetivo de la eliminación de la pobreza en la vejez... c) La habilitación de las personas de edad para que participen plena y eficazmente en la vida económica, política y social de sus sociedades... g) El reconocimiento de la importancia decisiva que tienen para el desarrollo social las familias y la interdependencia, la solidaridad y la reciprocidad entre las generaciones. h) La atención de la salud, el apoyo y la protección social de las personas de edad, incluidos los cuidados de la salud preventivos y de rehabilitación.

Por último, en la Carta de San José sobre los Derechos de las Personas Mayores de América Latina y el Caribe ${ }^{57}$, adoptada en la Tercera Conferencia Regional Intergubernamental sobre Envejecimiento, expresamente se señala que los Estados,... Conscientes de que la edad sigue siendo un motivo explícito y simbólico de discriminación que afecta el ejercicio de todos los derechos humanos en la vejez, y que las personas mayores requieren atención especial del Estado,... Convencidos de que es imprescindible tomar medidas adicionales para proteger los derechos civiles, políticos, económicos, sociales y culturales de las personas mayores, incluida la posibilidad de elaborar nuevos instrumentos internacionales...

Los Estados Latinoamericanos y del Caribe reafirman:

...el compromiso expresado en la Declaración de Brasilia de no escatimar esfuerzos para promover y proteger los derechos humanos y las libertades fundamentales de todas las personas mayores, trabajar en la erradicación de todas las formas de discriminación y violencia y crear redes de protección de las personas mayores para hacer efectivos sus derechos. Así como también, se comprometieron a reforzar las acciones dirigidas a incrementar la protección de los derechos humanos en el ámbito nacional y a: a. Adoptar medidas adecuadas, legislativas, administrativas y de otra índole, que garanticen a las personas mayores un trato diferenciado y preferencial en todos los ámbitos y prohíban todos los tipos de discriminación en su contra,

56 Dabove (2011a).

57 Carta de San José sobre los Derechos de las Personas Mayores de América Latina y el Caribe, de 2012. 
b. Fortalecer la protección de los derechos de las personas mayores por medio de la adopción de leyes especiales de protección o la actualización de las ya existentes, incluidas medidas institucionales y ciudadanas que garanticen su plena ejecución,

c. Brindar atención prioritaria y trato preferencial a las personas mayores en la tramitación, resolución y ejecución de las decisiones en los procesos administrativos y judiciales, así como en los servicios, beneficios y prestaciones que brinda el Estado, d. Adoptar medidas de acción afirmativa que complementen el ordenamiento jurídico y que promuevan la integración social y el desarrollo de las personas mayores,

e. Desarrollar políticas públicas y programas dirigidos a aumentar la conciencia sobre los derechos de las personas mayores, incluida la promoción de su trato digno y respetuoso y de una imagen positiva y realista del envejecimiento,

f. Garantizar y proveer los recursos necesarios para el acceso de las personas mayores a la información y a la divulgación de sus derechos,

g. Garantizar además el derecho a la participación de las personas mayores en las organizaciones de la sociedad civil y en los consejos, así como en la formulación, implementación y monitoreo de las políticas públicas que les conciernen.

Así pues, la referencia explícita de la Carta al respeto por los derechos humanos, al principio de igualdad y no discriminación y a la autonomía personal, incluso en el ámbito familiar, colocan a la problemática alimentaria de la vejez en un lugar óptimo para la construcción de un modelo de responsabilidad jurídica que resulte integral y acorde con el modelo de Estado Constitucional.

\section{b) RAZONES PARA LA CONSTRUCCión DE UN MODELO IUSFUndAMENTAL DE} RESPONSABILIDAD JURÍDICA EN LA VEJEZ

En Argentina, el modelo iusfundamental de responsabilidad jurídica en materia de alimentos en la vejez cuenta con destacadas herramientas constitucionales generales para su desarrollo. Así, en el plano normativo, cabe recordar la vigencia del "bloque de constitucionalidad" de los textos internacionales de Derechos Humanos mencionados en el artículo 75 inc. 22 de la Ley 24.430 Constitución de la Nación Argentina ${ }^{58}$. El reconocimiento expreso de la posibilidad de implementar leyes nacionales que contengan medidas de acción afirmativa respecto de la ancianidad, del art. 75 inc. 23. Como también es menester mencionar, la existencia constitucional de tres tipos de derechos humanos generales, perfectamente aplicables en las personas mayores. Los derechos de autonomía, referidos básicamente a la vida y a la salud, a las libertades, a la igualdad y a la propiedad. Los derechos de participación: entre los cuales un lugar destacado lo ocupa el derecho de alimentos, junto al derecho al trabajo, a la asociación, recreación, ocio y uso del tiempo libre. Los derechos de Prestación o Crédito: vinculados con la seguridad social; es decir, el derecho a pensión, jubilación; con el desarrollo y a la educación ${ }^{59}$.

\footnotetext{
58 Ley 24.430, de 1994.

59 VV.AA. (Dabove y Prunotto Laborde, 2013; Prieto Sanchís, 1990, 1994).
} 
En el plano ius sociológico, este modelo iusfundamental cuenta ya con la participación de importantes actores públicos y privados. Entre ellos, un lugar estratégico importante lo ocupan: la Dirección Nacional de Políticas para Adultos Mayores (DINAPAM) -de la Secretaría Nacional de la Niñez, Adolescencia y Familia-. La Administración Nacional de la Seguridad Social (ANSES), el Instituto Nacional de Seguridad Social para Jubilados y Pensionados (INSSJP-PAMI). Las Direcciones Provinciales de la Tercera Edad. Los organismos municipales de Promoción social y comunitaria. Los Foros para la Tercera Edad, de los Concejos Deliberantes. Las Defensorías del Pueblo. El Ministerio Público. Las Defensorías barriales, el poder judicial en general. Las Obras Sociales. Las escuelas y universidades. Sin embargo, cabe decir también que no todos ellos despliegan su accionar conforme a una mirada integral de los alimentos como derecho fundamental en la vejez. En este sentido es menester resaltar la impronta que tuvieron (y tienen aún) los famosos casos Badaro, Adolfo Valentín c. Administración Nacional de la Seguridad Social ${ }^{60}$ y Elliff, Alberto José c. Administración Nacional de la Seguridad Social ${ }^{61}$, entre otros, de la Corte Suprema de la Nación, que dieron lugar a la puesta en marcha de la Ley 26.417². Así como también, los cambios legislativos vinculados a la eliminación del Régimen de Capitalización (AFJP) y a la "publicización" del sistema previsional. Es decir, la vuelta al sistema estatal de reparto de jubilaciones y pensiones a través de la Ley $26.425^{63}$ y la ampliación de la cobertura previsional a las amas de casa y empleadas domésticas, entre otros, en cumplimiento del mandato previsto por el artículo 14 bis de la Constitución Nacional que expresa "El Estado otorgará los beneficios de la seguridad social que tendrá carácter de integral e irrenunciable".

Los valores plasmados en la Ley 24.430 Constitución de la Nación Argentina ${ }^{64}$ por los derechos fundamentales, nos instan a actuar a favor de este modelo. Plantean la necesidad de movilizar al Derecho en pos de una sociedad, una familia y un Estado que garanticen a cada persona mayor una esfera de libertad tan amplia -compatible con la de los demás-, que le permita desarrollar sus planes de vida y su personalidad senescente ${ }^{65}$. La justicia actual requiere, en suma, el sostenimiento de una sociedad plural, de una familia incluyente y de un Estado humanista, respetuosos de la unicidad de cada viejo, de la igualdad de la condición humana y de la vida comunitaria. Así, realidad social, normas y valores podrán articularse, en pos del modelo iusfundamental de responsabilidad jurídica que el envejecimiento multigeneracional actual reclama en materia de alimentos.

No obstante urge destacar también que en este nuevo modelo de responsabilidad jurídica alimentaria, un papel destacado debería ocuparlo la problemática de su cumplimiento en el ámbito de las Residencias Gerontológicas. Como se ya se ha dicho en otras investigaciones, en los Geriátricos suele verse desdibujado tanto el papel de las familias como el del propio Estado en esta materia. Las familias, por acogerse a prácticas abandónicas respectos

\footnotetext{
60 Badaro, Adolfo Valentín c. Administración Nacional de la Seguridad Social (2006) (2007).

61 Elliff, Alberto José c. Administración Nacional de la Seguridad Social (2009).

62 Ley 26.417, de 2008.

63 Ley 26.425, de 2008.

${ }^{64}$ Ley 24.430 , de 1994

65 Dabove (2002).
} 
de los ancianos que "depositan" en estas instituciones sin siquiera solicitarles su consentimiento. El Estado, por no asumir el desarrollo de una legislación nacional y de prácticas humanistas, que hagan realidad un sistema de derechos y garantías de corte iusfundamental en esta materia Derecho de la ancianidad y bioética en las residencias gerontológicas ${ }^{66}$.

\section{ALGUNAS CONCLUSIONES}

El Derecho actual vive, como vimos, atravesado por un fenómeno demográfico muy curioso, nunca visto en tiempos precedentes, que bien podría denominarse "envejecimiento multigeneracional". Este fenómeno se caracteriza por una estructura poblacional particular, fruto de los cambios sociales que generó el aumento de la esperanza de vida y el envejecimiento creciente y generalizado de la segunda mitad del silgo XX. Pero también, por la presencia de rasgos económicos y culturales especiales, no suficientemente asumidos por esta sociedad postmoderna; que inciden de manera directa en los esquemas tradicionales de responsabilidad jurídica frente a la vejez.

Nuestro Derecho no resulta ajeno al envejecimiento multigeneracional, dado que sus efectos impactan en muchas de sus instituciones, tanto en sentido positivo como negativo. Así por ejemplo, su desarrollo pone en crisis el régimen de la capacidad de las personas en general. Afecta la tutela y curatela y la adopción. Tiene impacto sobre el matrimonio y la unión convivencial; o sobre la separación personal y el divorcio vincular. Pero también altera el ejercicio del derecho a la vida, a la salud y a la integridad física y moral de cada sujeto y de cada generación, pudiendo desencadenar situaciones de violencia familiar de extrema complejidad en su resolución. Ahora bien, como los ancianos -por otra parte-, suelen estar muy débilmente posicionados en este entramado social, son ellos quienes terminan soportando el mayor peso de las consecuencias jurídicas negativas de este envejecimiento multigeneracional. Lamentablemente, el derecho de alimentos suele ser una de las instituciones que más claramente ilustran las consecuencias negativas que provoca la no asunción del derecho de alimentos en la vejez, a la luz del paradigma Neoconstitucional de los Derechos Humanos en Argentina.

\section{BIBLIOGRAFÍA CITADA}

AleXY, Robert (1997): El concepto y la validez del derecho (2a ed., Trad. Jorge M. Seña, Barcelona, Gedisa).

Alexy, Robert (2008): Teoría de los derechos fundamentales (2a ed., Trad. Carlos Bernal Pulido, Madrid, Centro de Estudios Políticos y Constitucionales).

BAzo, María Teresa (1993): "La vejez como problema social”, en Sánchez Vera, Pedro (edit.), Sociedad y Población Anciana (Murcia, Universidad de Murcia) pp. 181-192.

Bauman, Zygmunt (1999): Modernidad líquida (Buenos Aires, Fondo de Cultura Económica).

Bauman, Zygmunt (2000): Trabajo, consumismo y nuevos pobres (Barcelona, Gedisa).

${ }^{66}$ Dabove (2011b) pp. 4-16, (2012) pp. 3-58. 
Bauman, Zygmunt (2006a): Vidas desperdiciadas. La modernidad y sus parias (Trad. Pablo Hermida Lazcano, Buenos Aires, Paidós).

Bauman, Zygmunt (2006b): Comunidad. En busca de seguridad en un mundo hostil (Madrid, Siglo XXI).

Bauman, Zygmunt (2007a): Vida de consumo (Trad. Mirta Rosenberg y Jaime Arrambide, Buenos Aires, Fondo de Cultura Económica).

Bauman, Zygmunt (2007b): Tiempos líquidos (Barcelona, Tusquets).

Bellina Yrigoyen, Jorge (2004): La economía politica de los fondos de pensiones (Rosario, UCEL).

Belluscio, Augusto César (1987): Manual de Derecho de Familia. Tomo II. (5ª ed., Buenos Aires, Depalma).

Bidart CAmpos, Germán J. (2002): "Una sentencia que supo dar curso efectivo a los derechos sociales, encontrar al sujeto pasivo y determinar su obligación ", La Ley, Tomo 2002-E: p. 267.

Bobbio, Norberto (1991): El tiempo de los derechos (Trad. Rafael de Asís Roig, Madrid, Sistema).

Borda, Guillermo A. (1989): Tratado de Derecho Civil. Familia. Tomo 1 y 2 (8a ed., Buenos Aires, Perrot).

Bossert, Gustavo. A. (2004): Régimen jurídico de los alimentos (2a ed., Buenos Aires, Astrea).

Bossert, Gustavo A. y Zanonni, Eduardo A. (2013): Manual de Derecho de Familia (6a ed., Buenos Aires, Astrea).

Braudel, Fernand (1986): Las civilizaciones actuales. Estudio de Historia Económica y Social (Trad. J. Gómez y Mendoza y Gonzalo Anes Madrid, Tecnos).

Briones, Claudia (1998): La alteridad del cuarto mundo (Buenos Aires, Colihue).

Calvo Ortega, Rafael y Garcia Calvente, Yolanda (2007): Situaciones de dependencia: regulación actual y nuevas perspectivas (Pamplona, Thomson - Civitas).

Ciuro Caldani, Miguel Ángel (1992): "Derecho de la Ancianidad", Investigación y Docencia, No 20: pp. 35-40.

Ciuro Caldani, Miguel Ángel (1995): “Comparación jusfilosófica del Derecho de Menores y el Derecho de la Ancianidad”, Investigación y Docencia, No 25: pp. 7-11.

Ciuro Caldani, Miguel Ángel (2002): "Un pronunciamiento con amplias proyecciones problemáticas: Notas de filosofía de la propiedad”, La Ley, Tomo 2002-E: p. 270.

Córdoba, Marcos M. y Solari, Néstor E. (1990): "Nuevas normas legales rigen la materia alimentaria", La Ley, Tomo 1990 B: p. 1189.

Dabove, María Isolina (1999): "Violencia y ancianidad", Doctrina Judicial, 34: pp. 11651172.

Dabove, María Isolina (2002): Los derechos de los ancianos (2a ed., Ciudad de Buenos Aires, Ciudad Argentina).

Dabove, María Isolina (2008): "Derecho y multigeneracionismo: o los nuevos desafíos de la responsabilidad jurídica familiar en la vejez", Revista de Derecho de Familia, $\mathrm{N}^{\circ} 40$, julio/agosto: pp. 39-54.

Dabove, María Isolina (2011a): "Autonomía y atención de las personas mayores en situación de dependencia en España: Una cita entre generaciones”, Ancianidad, Derechos 
Humanos y Calidad de Vida: Nuevos desafíos para la autonomía, la igualdad y la no discriminación en la vejez (Oñati, País Vasco, Instituto Internacional de Sociología Jurídica de Oñati, Oñati Socio-Legal Series, v. 1, n. 8).

Dabove, María Isolina (2011b): "Derecho de la ancianidad y bioética en las instituciones geriátricas”, Revista: Jurisprudencia Argentina. Número especial, 2011-III, fascículo 13: pp. 4-16.

Dabove, María Isolina (2012): "En el tiempo de los derechos: una mirada iusfundamental a las residencias gerontológicas", Revista: Jurisprudencia Argentina, 2012-I, fascículo 4: pp. 3-58).

Dabove, María Isolina y Prunotto Laborde, Adolfo (2013): Derecho de la ancianidad: perspectiva interdisciplinaria (2a ed., Rosario, Juris).

Daniels, Norman (1988): Am I my parents' keeper? An essay on justice between the young and the old (New York, Oxford University Press).

De Souza Minayo, María Cecilia (2006): "Visâo antropológica do envelhecimento humano”, en: Velhices. Reflexôes contemporáneas (San Pablo, PUC-SP) pp. 47-59.

Di Tullio Budassi, Rosana (2008): “El Derecho alimentario de los ancianos”, Derecho de Familia. Revista Interdisciplinaria de Doctrina y Jurisprudencia, N³8: pp. 64-82.

Dworkin, Ronald (1989): Los derechos en serio (2a ed., Barcelona, Ariel).

Dworkin, Ronald (1992): El imperio de la justicia (2a ed., Barcelona, Gedisa).

Fama, M. Victoria y Herrera, Marisa (2008): "La obligación alimentaria de los abuelos hoy”, Revista Jurídica online El Dial, No 2659, Suplemento Especial 17/11/2008.

FANZOLATO, Eduardo Ignacio (1991): Alimentos y reparaciones en la separación y en el divorcio (Buenos Aires, Depalma).

Fanzolato, Eduardo Ignacio (1996): "Los ancianos y la solidaridad familiar en el siglo XXI", Revista de la Facultad, Universidad Nacional de Córdoba, Facultad de Derecho y Ciencias Sociales, Volumen 4, N²: pp. 11-40.

Fanzolato, Eduardo Ignacio (2007): Derecho de familia. Tomo I. (Córdoba, Advocatus).

Garcés Ferrer, Jordi (1992): Administración Social Pública. Bases para el estudio de los Servicios Sociales (Valencia, Tirant lo Blanch).

GEERTZ, Clifford (2006): Los usos de la diversidad (Barcelona, Paidós).

GuAstini, Ricardo (2001): Estudios de teoría constitucional (México, Fontamara).

Herrera, Marisa (2011): "Estado, ciudadanía y democracia. Algunos silenciados del derecho de familia: el papel de los abuelos en la familia del siglo XXI", Jurisprudencia Argentina", 16 de marzo de 2011: pp. 4-20.

IACUB, Ricardo (2011): Identidad y envejecimiento (Buenos Aires, Paidós).

IACUB, Ricardo (2012): El poder en la vejez (Buenos Aires, INSSJP).

Instituto de Mayores y Servicios Sociales (1990): La tercera edad en España: necesidades y demandas (Madrid, Ministerio de Asuntos Sociales).

Instituto Nacional de Estadísticas y Censos (INDEC) (2012): Censo nacional de población, hogares y viviendas 2010: censo del Bicentenario: resultados definitivos (Buenos Aires, INDEC, Serie B No 2).

JÁuregui, Rodolfo G. (2002): "Hambre, amparo y anticipo de tutela jurisdiccional”, La Ley Litoral, 2002: p. 847. 
Jelin, Elizabeth (1998): Pan y afectos. La transformación de las familias (Buenos Aires, Fondo de Cultura Económica).

Kemelmajer De Carlucci, Aída (2006): "Las personas ancianas en la jurisprudencia argentina ¿Hacia un Derecho de la Ancianidad?”, Revista Chilena de Derecho, Vol. 33, No 1: pp. 37-68.

Kymlica, Will (1995): Ciudadanía multicultural (Barcelona, Paidós).

LEBRUN, François (1992): "Las reformas: devociones comunitarias y piedad personal”, en: Aries, Philipe y Duby, Georges (dirs.), Historia de la vida privada. El proceso de cambio en la sociedad de los siglos XVI-XVIII, Tomo 5 (Madrid, Taurus) pp. 71-112.

Lloveras, Nora y Salomon, Marcelo (2009): El Derecho de Familia desde la Constitución Nacional (Buenos Aires, Universidad).

Méndez Costa, María Josefa (1983): "Los ancianos en la Legislación Civil”, La Ley. Buenos Aires, Tomo 1983 A: p. 315.

Méndez Costa, María Josefa (2000): Visión Jurisprudencial de los Alimentos (Santa Fe, Rubinzal-Culzoni).

Méndez Costa, María Josefa y D’Antonio, Daniel Hugo (2001): Derecho de Familia. Tomo III. (Buenos Aires, Rubinzal-Culzoni).

Menezes Da Costa, Maria Aracy (2012): "Alimentos y abuelos: los abuelos no son padres dos veces!", en: Libro de Disertaciones y Ponencias del XVII Congreso Internacional de Derecho Familiar (Buenos Aires, La Ley - AbeledoPerrot) pp. 120-132.

Moix Martinez, Manuel (1986): Bienestar Social (2a ed., Madrid, Trivium).

Montero Garcia, Feliciano (1988): Los seguros sociales en la España del siglo XX. Orígenes $y$ antecedentes de la previsión social (Madrid, Ministerio de Trabajo y Seguridad Social).

Oliva Gómez, Eduardo (2012): "El cumplimiento de la obligación alimentaria a favor de los adultos mayores. Hacia la protección de este grupo vulnerable en el Derecho de Familia”, en Libro de Disertaciones y Ponencias del XVII Congreso Internacional de Derecho Familiar (Buenos Aires, La Ley - AbeledoPerrot) pp. 142-155.

Organización de las Naciones Unidas (ONU) (1982): Primera Asamblea Mundial sobre el Envejecimiento, Viena, 26 de julio a 6 de agosto de 1982. Plan de Acción Internacional de Viena sobre el Envejecimiento. Disponible en: <http://www.imsersomayores.csic.es/documentos/documentos/asamblea-planviena-01.pdf> [fecha de consulta: 25 de junio de 2013].

Organización de las Naciones Unidas (ONU) (2002): Segunda Asamblea Mundial sobre el Envejecimiento Madrid, España, 8 a 12 de abril. Plan de Acción Internacional de Madrid sobre el Envejecimiento 2002. Disponible en: <http://social.un.org/index/Portals/0/ ageing/documents/Fulltext-SP.pdf>.

Prieto Sanchís, Luis (1990): Estudio sobre Derechos Fundamentales (Madrid, Debate).

Prieto SAnchís, Luis (1994): "Minorías, respeto a la disidencia e igualdad sustancial", Doxa, No 15-16: pp. 367-387.

Prieto SANChís, Luis (2002): Derechos Fundamentales, neoconstitucionalismo y ponderación judicial (Lima, Palestra). 
Salomon, Marcelo y JÁuregui, Rodolfo G. (2007): "La Constitución Nacional y la obligación alimentaria de los abuelos: una mirada integradora”, La Ley Buenos Aires, julio: p. 605.

SARTORI, Giovanni (2001): La sociedad multiétnica. Pluralismo, multiculturalismo y extranjeros (Taurus. Madrid).

TAYlor, Charles (1993): Multiculturalismo y la política del reconocimiento (México, Fondo de Cultura Económica).

Trevelyan, G. M. (1946): Historia Social de Inglaterra (Trad. Adolfo Álvarez Buylla, México, D.F., Fondo de Cultura Económica).

Yturbe, Corina de (2008): Multiculturalismo y derechos (México, D.F., Instituto Federal Electoral). Disponible en: <http://biblio.juridicas.unam.mx/libros/1/490/1.pdf>.

YubA, Gabriela (2011): "La obligación alimentaria de los abuelos a favor de los nietos", $R e-$ vista de Derecho de Familia y de las Personas, Año 3, No 6, julio: pp. 77-87.

Zannoni, Eduardo (1993): Derecho Civil. Derecho de Familia (Buenos Aires, Astrea, Tomo 1).

\section{NORMAS CITADAS}

Código Civil de la República Argentina. Buenos Aires: AbeledoPerrot, 2013.

Ley No 24.241 del 23 de septiembre de 1993, Sistema Integrado de Jubilaciones y Pensiones. Disponible en: <http://www.infoleg.gob.ar/infolegInternet/anexos/0-4999/639/ norma.htm> [fecha de consulta: 25 de junio de 2013].

Ley No 24.430 del 14 de diciembre de 1994, Constitución de la Nación Argentina. Disponible en: <http://infoleg.mecon.gov.ar/infolegInternet/anexos/0-4999/804/norma.htm $>$ [fecha de consulta: 25 de junio de 2013].

Ley 26.417 del 1 de octubre de 2008, Movilidad de las Prestaciones del Régimen Previsional Público. Disponible en: <http://infoleg.gov.ar/infolegInternet/anexos/145000-149999/145867/norma.htm> [fecha de consulta: 16 de julio de 2013].

Ley No 26.425 del 20 de noviembre de 2008, Sistema Integrado Previsional Argentino. Disponible en: <http:/www.infoleg.gob.ar/infolegInternet/verNorma.do;jsessionid=CD3E6B 9D852E6ED7A1075711FC87C4FE?id=148141> [fecha de consulta: 2 de julio de 2013].

Ley No 39 del 14 de diciembre de 2006, De Promoción de la Autonomía Personal y Atención a las Personas en Situación de Dependencia. Disponible en: <http://www.boe.es/boe/ dias/2006/12/15/pdfs/A44142-44156.pdf > [fecha de consulta: 5 de julio de 2013].

Carta de San José sobre los Derechos de las Personas Mayores de América Latina y el Caribe (2012), adoptada en la Tercera Conferencia Regional Intergubernamental sobre Envejecimiento en América Latina y el Caribe. Disponible en: <http://www.cepal.org/ celade/noticias/paginas/1/44901/CR_Carta_ESP.pdf > [fecha de consulta: 2 de julio de 2013].

\section{JURISPRUDENCIA CITADA}


A.D.P., en representación de sus hijos menores A. F., J. C. y M. E. F. c. A. A. F. y N. R. G. (2010): Juzgado de Familia No 1 de Mendoza, 29 de noviembre de 2010, Revista de Derecho de Familia y de las Personas, Año 3, No 6, julio 2010, p. 77.

Badaro, Adolfo Valentín con Administración Nacional de la Seguridad Social (2006): Corte Suprema de Justicia de la Nación, 8 de agosto de 2006, La Ley, Tomo 2006-D, p. 801.

Badaro, Adolfo Valentín con Administración Nacional de la Seguridad Social (2007): Corte Suprema de Justicia de la Nación, 26 de noviembre de 2007, La Ley, 2007-F, p. 688.

B.A.F. con Provincia de Buenos Aires S/ Amparo. (Recurso Extraordinario de Inaplicabilidad) de Ley (2013): Corte Suprema de LA Provincia de Buenos Aires, 3 de julio de 2013, A-70138, Sitio web de la http://www.scba.gov.ar/jurisprudencia [fecha de consulta: 26 de julio de 2013]

B., L. E. v. C., D. y otra (2007): Tribunal Familiar de Quilmes, 18 de abril de 2007, La Ley Buenos Aires, julio 2007, p. 606.

C. de T., J. E. C/ T., N. y otro (1981): Cámara Nacional Civil, sala G, 29 de septiembre de 1981, en: Barbado, Analía R. y Barbado, Patricia B. Alimentos según la Jurisprudencia (Buenos Aires, Ad-Hoc, 2003) p. 131.

C., M. L. v. L., L. R. y otros (2006): Cámara Civil de Neuquén, sala 3a 18 de abril de 2006, La Ley Patagonia, p. 636.

Defensor del Superior Tribunal de Justicia con Provincia de Entre Ríos (2002): Juzgado de Menores Nro. 2 de Paraná, 21 de julio de 2002, La Ley, Tomo 2002-E, p. 271.

Elliff, Alberto José con Administración Nacional de la Seguridad Social (2009): Corte Suprema de Justicia de la Nación, 11 de agosto de 2009, Sitio web de la Corte Suprema de Justicia de la Nación http://www.csjn.gov.ar/co_[fecha de consulta: 16 de julio de 2013].

Fallo de la Cámara Nacional Civil Sala C (1979): Cámara Nacional Civil Sala C, 24 de abril 24 de 1979, La Ley, Tomo 1979-D, p. 206.

Fallo de la Cámara Nacional Civil Sala F (1983): Cámara Nacional Civil, Sala F, 25 de abril 25 de 1983, La Ley, Tomo 1983-D, p. 229.

Fallo de la Cámara Nacional Civil Sala G (1983): Cámara Nacional Civil Sala G, 16 de septiembre de 1983, La Ley, Tomo 1984-C, p. 637.

Fallo de la Cámara Nacional Civil Sala D (1986): Cámara Nacional Civil Sala D, 26 de marzo de 1986, La Ley, Tomo1987-A, p. 673.

G. F. C. c/ I. T. M. E. C. s/ alimentos (2012): Cámara Nacional Civil Sala B, 12 de marzo de 2012, El Dial AA75F3, 5 de agosto 2012.

M. de H., L. c/H. de F., C. D. (1990): Cámara Civil y Comercial de Córdoba, 20 de marzo de 1990, La Ley, Tomo 1990 C p. 710.

Y., J. D. v. T., A. D. y T. M. A. (2009): Cámara Civil y Comercial de Azul, sala 2a, 30 de abril de 2009, La Ley Buenos Aires, junio 2009, p. 537.

W. J. A. c/ F., M. A. s/ Abreviado. Regulación de Honorarios (2012): Juzgado de Primera Instancia Civil y Comercial 15a Nom-Sec de Córdoba, Auto 352 del 31 de mayo de 2012, Expte. 2229763/36. 
